\title{
Rural Development Through Communal-based Enterprises In Selected Districts Of Lesotho
}

Leseko Makhetha ( $\nabla$ makhetha2019@isscad.pku.edu.cn )

Peking University https://orcid.org/0000-0003-4337-067X

\section{Ramakae Liphoto}

National University of Lesotho

Makara Mahamo

National University of Lesotho

Nkopane Manong

National University of Lesotho

Motlalepula Mokhethi

National University of Lesotho

\section{Research}

Keywords: Communal-Based Enterprises, Basotho Enterprises Development Corporation, Rural Household Development, Lesotho

Posted Date: February 25th, 2020

DOI: https://doi.org/10.21203/rs.2.24549/v1

License: (c) (i) This work is licensed under a Creative Commons Attribution 4.0 International License.

Read Full License 


\title{
RURAL DEVELOPMENT THROUGH COMMUNAL-BASED ENTERPRISES IN SELECTED DISTRICTS OF LESOTHO
}

\author{
Makhetha S. Leseko*: makhetha2019@isscad.pku.edu.cn (corresponding author) \\ Liphoto R. Ramakae**: retselisitsoeliphoto@gmail.com \\ Mahamo S. Makara**: $\quad$ makaramahamo@gmail.com \\ Manong S. Nkopane**: nsmanong@gmail.com \\ Mokhethi A. Motlalepula**: mmokhethi7@gmail.com
}

*Peking University; National School of Development; 100871 Beijing China.

**National University of Lesotho; Economics Department; P.O. Roma 180; Maseru 100; Lesotho. 


\section{A B S T R A C T}

In an attempt to improve the livelihoods of rural households, different approaches to rural development have been adopted in different economies. The most broadly adopted approaches have been technocratic, the radical and the reformist approach. These approaches are unique in that they aim at achieving different rural developmental objectives. Despite different approaches that are been used in the literature, in this paper, central to rural community development is the communal-based enterprises approach with an implicit research objective of assessing how Basotho Enterprises Development Corporation can contribute in enhancing livelihood development and thus sustaining the community at large. The results show that enthusiasm is high in all villages as a majority of interviewees showed a positive initiative capacity in which the only barrier pulling them back is a pushing force. This barrier can be justified as the majority of people have no knowledge of Basotho Enterprises Development Corporation and the services they provide.

Key words: Communal-Based Enterprises, Basotho Enterprises Development Corporation, Rural Household Development, Lesotho. 


\section{B A C K G R O U N D}

Three of five people in Lesotho are rural households of which $59.6 \%$ of these households are living below the poverty line (National Institute of Statistics, Directorate General for Health and ICF International, 2015). Some of the underlying attributes for high poverty levels are the increasing unemployment, rarity of resources and lack of financial support. The increasing scarcity of resources, environmental degradation as well as the hiking poverty levels in the rural communities has led to out-migration to the already overcrowded cities at the rate of $3.5 \%$ per annum in Lesotho (World Urbanization Prospects, 2019). This migration movement, however, is exposed to increasing insecurity and social violence with marginalized possibilities of sustained income. Meanwhile, migrants are risking the disintegration of families, the burden often on women and children and escalating economic hardships. All these problems still continue to escalate even today despite the awareness made by the (United Nations, 2001) in the past two decades that if these problems are not aggressively addressed, poverty and social insecurities will persist in the entire societies of Sub-Saharan African (SSA) countries in which case Lesotho is included.

In the specific case of Lesotho, several community-based projects have been implemented with the prime objective of sustaining the livelihoods of the poor rural households but oftentimes they failed to meet the needs of these households. These projects vary from agricultural projects to water projects to food security projects. Most if not all of these projects barely see a decade. Those that survive, often benefit the few privileged households, ignoring the needs of poor households. These daunting socio-economic conditions are not the experiences of SSA countries alone, China has also gone through a similar experience, even worse, before rural reforms in 1978. But why have China's rural reforms proven to be successful while the rest of 
SSA countries that underwent similar reform processes are still stuck in escalating poverty levels? What approach did China adopt in reforming its rural policies, which makes it outperform any rural reform ever designed in all human history? What are the lessons to be learned? These questions have attracted a lot of debates in the rural development literature, both at policy level and among scholars.

Resultantly, in an attempt to improve the livelihoods of rural households, different approaches to rural development have been adopted in different economies. The most broadly adopted approaches have been technocratic, the radical and the reformist approach. These approaches are unique in that they aim at achieving different rural developmental objectives. For instance, (Cheema and Shah, 1987) indicate that the technocrat approach puts more emphasis on infrastructure and agriculture reforms, while the radical approach aims at social development and equity reallocation of power within the society with a skewed emphasis towards empowering the most disadvantaged rural households. The reformist approach as explained by (Cheema and Shah, 1987) in contrast, aims at redefining the optimal strategy in dealing with the conflicts that exist within the rural communities. Unlike the radical approach, the reformist approach further targets equity distribution of wealth amongst the rural households. To achieve each of the approaches, one or combination of following four-folds of strategies oftentimes are employed; 1) the top-down (commonly known as bureaucratic) strategy, 2) the outside-in (also called commercialisation) strategy, 3) the bottom-up (referred to as participation) strategy, and 4) the inside-out (commonly called mobilisation) strategy).

Despite different approaches that are been used in the literature, in this paper, central to rural community development is the communal-based enterprises (CBE) which in literature has 
multiple definitions. Nevertheless, this paper adopts a definition by (Parwez, 2017) who defines CBE as a community acting corporately as both entrepreneur and enterprise in pursuit of a common goal. (Parwez, 2017) emphasizes that CBE is a result of a process in which the community acts entrepreneurially to create and operate a new enterprise embedded in its existing social structure. In line with this definition, it is implied that CBEs are governed by the socio-economic interests of a community in a way that is both profitable and sustainable to individuals and groups alike over the short-term and long-term.

For desired outcomes, (Hughey, Speer and Peterson, 1999) postulate that initiating local enterprises for communal sustainability requires a pensive understanding of societal arrangements, diverse macro-environmental conditions, and community perspective about developments as well as cultural values of the community in which such a development is to take place. While (Hughey, Speer and Peterson, 1999) observations are plausible, the need to understand that the individual societal development plan at a rural level is equally important as value creation and innovation through developing local enterprises using indigenous natural resources is also compelling. Hence, this prompts the essentiality of inter-connectedness amongst the state, the market, and the society to make the best use of local resources in fighting against socio-economic problems prevailing within rural households.

Beside the state agencies, many other interested groups including international organisation have intervened in Lesotho rural reforms, and rural development projects, the implementation has often deemed to be flawed. It is thus puzzling that, even though these projects have proven to be unsuccessful, to the best of my knowledge no different approach that will bind both the state, the market and the society have been employed. In view of the foregoing, the objective 
of this paper, therefore, is to assess community perception on community-based entrepreneurship through a case study approach with an implicit research question on how BEDCO $_{1}$ can contribute in enhancing livelihood development and thus sustaining the community at large. In particular, the study seeks to address the following questions: (1) what are communities' perspectives about community-based enterprises? (2) What local natural resources are available that can be utilized for community's entrepreneurial purposes? (3) What are communities' expectations from BEDCO in relation to enterprise development? Finally, the study will seek to determine 'BEDCO - community' awareness index which captures the scale at which BEDCO roles are known within rural communities.

This case study contributes to the existing literature on rural development in LDC. On the policy front, will contribute to discussions in Lesotho on how to develop rural communities making the best use of available resources. The most conspicuous result is that community know very little about BEDCO and its engagement in community development projects, thus raising BEDCO aware remains central in $\mathrm{CBE}$. The rest of the paper is structured as follows: Section 2 reviews the literature while Section 3 highlights data collection, methods and results analysis. Finally, Section 4 concludes the paper.

\footnotetext{
${ }^{1}$ Basotho Enterprises Development Corporation (BEDCO) is a parastatal of the Lesotho Government. It started its operations in 1975 as the subsidiary company of Lesotho National Development Corporation (LNDC). It was established as a parastatal in 1980 by an ACT of Parliament, ACT NO. 9 of 1980, as amended, as the arm of Government, under the Ministry of Trade and Industry, Cooperatives and Marketing (MTICM) that establishes and promotes Basotho owned business.
} 


\section{L I T E R E A T UR E R E V I E W}

\subsection{THE STATE, THE MARKET, AND THE SOCIETY IN CBE}

Community development theory and practice has come a long way and has become more mature over the years. Alongside this maturity, the ideology of community development has grown over the years to the present, from the evolutionary paradigm, through the conflict and functionalist theoretical model to the advent of the complexity theory model in a post-modern 21 st century. Nonetheless, these theories lack one thing in common; the ability to demonstrate how between the state, the market and the society interplay for the welfare of the entire society. Consequentially, community development became associated with selfish individuals, politicians and organizations who used community development programs for their personal interest. This background contaminated the concept of community development such that it has become one of the most exploited concepts by members from target communities to demand unrealistic services and facilities.

With the increasing importance of interaction between the state, the market and the society, wrestling with the balance between the state, the market and the society has been a constant debate in development literature. As rightly postulated by (Eclac-un et al., 2002) in the field of economic policymaking, the question to ask is not that of whether state or the market or the society, but rather that of how to balance the three. Thus, it takes not two, but three to tango in economic policymaking. China exemplifies a clear interaction amongst these three concepts through dual-tracking pricing. For instance, in the absentia of the market pre-1978, the statecontrolled the prices in the market through the central planning economy. During that time, China's gross domestic product (GDP) hovered around five percent. However, after the reform 
and opening up in 1978 , the state market, the market, and the state were allowed to interlace in order to improve societal wellbeing. Since then, China's growth record as noted by (Stiglitz, 1996) has never been paralleled in all human history. Central to the growth miracle of China has been the right alignment government policies, market incentives and public pressure to enforce development.

In an attempt to sustain marginalized rural households, development agencies and multinational organizations have for decades been working side by side with different development programs. This includes the likes of the World Bank's international development association transfer program in Lesotho (World Bank, 2018). The widely adopted approaches have been in the form of charity that ignores the most crucial demands and perspectives of the local communities as opposed to building sustainable projects. Consequently, these approaches prompted the creation of real socio-economic problems such as poverty within marginalized rural households rather than alleviation. Most importantly, these approaches have often led to a lack of ownership on the part of the local community and beneficiaries.

It is therefore evident that the interaction between the state, the market and society has always been the greatest challenge for least developed economies in reforming their policies. This is particularly so because these economies oftentimes adopt either top-down or bottom-up approaches in designing policies. The typical example of the top-down approach that has cut across these economies is the Washington Consensus2. The Washington Consensus is a Western-based development policy for least developed economies (Klees, 2008).

\footnotetext{
2 Washington Consensus is a set of 10 Washington D.C. - based institutions economic policy recommendations varying from macroeconomic stabilization policies to economic opening up of international trade, with the aim of boosting economic development in LDC.
} 
Unfortunately, these policymakers (Westerners) know very little about each country's specific underlying development challenge, and their policies are generic for all economies. Perhaps this also explains why the Washington Consensus failed. On the contrary, the bottom-up policy approach involves laymen taking a lead role in finding solutions hindering development. Unless these two approaches are consolidated through a proper synthesis of the state, the market and the society, desirable results are oftentimes implausible.

\subsection{MICRO-SMALL MEDIUM ENTERPRISE OVERVIEW IN LESOTHO}

According to (FinScope Lesotho, 2015) an estimated 120000 people work in the Micro-Small Medium Enterprise (MSME) sector in Lesotho, including MSME owners. As such, the sector provides a huge opportunity for job creation as currently, only $7 \%$ of the adult population is working in the sector. Furthermore, it contributes to poverty alleviation as survivalist businesses play a very crucial role, especially as a buffer against slipping into deeper poverty and as such reducing individual and household vulnerability. The estimated monthly turnover of the MSME sector in 2015 was estimated to be at least 192 million Maloti. This only constitutes $75 \%$ of MSME owners who reported their turnover. In addition (Khoase and Govender, 2013) posit that 59\% of MSME owners are female and almost haft of MSME owners are rural households. The authors further postulate that $61 \%$ of these MSME owners have some secondary level of education and better. However, $78 \%$ of them acquired their business skills informally through internal networks (family, friends, other business owners) or whilst managing the business. 
The MSME sector in Lesotho is largely driven by wholesale that constitutes $52 \%$, retail and agriculture. Around $30 \%$ of MSME owners claim to work in the wholesale and retail sector mainly selling goods or services in the same form. About 1 in 4 MSME owners (22\%) reported to operate in the agriculture sector, largely $(53 \%)$ rearing livestock with only $15 \%$ growing crops. Another $10 \%$ and $9 \%$ of MSME owners claim to work in accommodation and food services, and manufacturing respectively. MSMEs in Lesotho are relatively established; the majority $(64 \%)$ reported that their businesses are more than 3 years in operation. In total, $18 \%$ of MSME owners reported that their businesses are registered. Of the registered MSMEs, $82 \%$ are owned by individuals (sole proprietors), $6 \%$ are companies and $5 \%$ are in partnership. Chapter 2 contains a thorough discussion of literature, followed by an outline of data collection methods and its analysis in chapter 3 . We then conclude and give recommendations in the last chapter. The appendix will show a copy of our questionnaire including additional information.

\subsection{LAYING FOUNDATIONSFORCBE}

One of the most important characteristics of enterprise development within societies is the view that prevails in them of the nature of the community (Peredo and Chrisman, 2006). They further state that the more community-oriented a society is, the more its members will be entitled to certain societal benefits, including the satisfaction of needs connected with survival, such as basic income, health care, and safety. So, community developers should acknowledge the potential of local entrepreneurs as it is stated that it would lead to remarkable developments in the local economy. Communities can, over time, improve their entrepreneurial ecosystem by focusing on the needs and wants of entrepreneurs since entrepreneurs are not all the same. Communities must be flexible and responsive to meet the varying needs of entrepreneurs. It is 
essential that support is tailored to fit the needs and wants of entrepreneurs, rather than based on satisfying an external agency or funding source. Furthermore, to develop sustainable entrepreneurship in a community, it is rarely sufficient to change just one element in the ecosystem. Instead, community developers and local leaders must change several elements (including culture, quality of human capital, availability of appropriate finance among others) simultaneously.

It has been argued that investment social capital is key to successful CBE. A recent study by (Pittaway and Thorpe, 2012) on meaning and applications of social capital show that as individuals work together as one with the same values they are more likely to succeed. In the 1980s, the importance and relevance of social contacts and networks became more appreciated thus values assumed through contact with family and friends enables entrepreneurs to generate more favourable perceptions of desirability to create firm (Liñán and Santos, 2007). In enterprise formation, network not only provides a social resource) but also gives the individual self-confidence, support and motivation.

One of the earliest contemporary analyses of social capital was of the economists (Murphy, 1948; Portes, 2009) who argued that the customary theories were too individualistic. Though he did not develop the concept of social capital in detail, he states that "the married notion that in a free society, each individual will rise to a level justified by his or her competence conflicts with the observation that no one travels that route entirely alone". (Murphy, 1948)'s early work paved the way for other theorists, one of which is Davis (1993), who stated that to alleviate poverty, development agencies and multinational organizations have been greatly involved in interventions in the developing world for many decades. It has been observed that the most 
widely adopted approaches have often been paternalistic, even unintentionally, while ignoring the strength of local institutions. A major issue in developmental activities is that projects are generally conceived and implemented by agencies rather than community members. This has often led to a lack of ownership on the part of the local population and beneficiaries.

Upon laying foundations for CBE, the most obvious concern lies in challenges faced with CBE. Albeit, evidence suggests that a possibility of cultural identity may function as a tool for entrepreneurial activity, it appears that entrepreneurial activity can flourish in a diverse and dynamic societal and good government policies and conducive market environment [see for instance (Parwez, 2017)]. However, these remarkable observations do not rule out the challenges facing CBE. Most of these challenges are socio-oriented. For instance, (Cavaye, 2001) emphasizes the interaction between development state agencies and the community that it has implications for the success of CBE.

Also, societal attitude towards the planned development project has born a strong deterministic long-term survival of the project, particularly if societal perceptions about the project are overlooked. Another challenge is that of confidence. According to (Cavaye, 2001) the difficulties many communities have in taking or maintaining action is not necessarily due to lack of venture capital, poor access to funding, or limits to community engagement, rather difficulties exist because the society struggle to discern a clear direction for action and lack of confidence to act. Finally, the other external factor found to be directly affecting the success of community development projects is poor rural infrastructure (rural electrification and roads). These two factors are crucial particularly for the storage of agricultural production and accessibility to key community resources. 
On the empirical front, a substantial body of empirical evidence has been written on the subject of $\mathrm{CBE}$ by a number of authors worldwide. Each of their separate studies outlines a unique approach and attributing do contradicting assertations made on CBE. Although least developed countries (LDC) communities share several commonalities, it is equally important to note the discrepancy that may evolve from culture due to continental disconnectedness. Thus, to remove any bias this paper cuts across multiple authors from separate regions of the world with a particular focus on developing economies.

In Asian countries (Parwez, 2017) conducted a study in Gujarat, rural India, to find out whether community-based entrepreneurship alleviates poverty. In this research, the author used qualitative research approach using primary data in which the author concentrated on a single case study of Friendly Mart in order to understand community-based entrepreneurship, thus results and activities are limited to a single occurrence. The results indicated that the deprived socio-economic status of the Muslim community can be considered as a key determinant of entrepreneurial activity. The results further suggested that entrepreneurship among a Muslim community characteristically emerges in an environment of economic stress, drawing from the community's tradition of helping each other.

In Myanmar, (Martin and Osberg, 2015) have indicated that poor rural households cannot afford agricultural inputs, therefore in order to improve the rural welfare, rural households should have access to microcredit to support agricultural productivity. Resultantly the government established Proximity - a non-profit social enterprise that works hand in hand with rural agriculture. Proximity, therefore, engages deftly with the government, which considers it a trusted adviser on issues of food security and as a resource for training agricultural officers. 
This, in turn, has increased agricultural output and market demand, with substantially improved food security and livelihood for millions of rural households in Myanmar.

In a similar manner, (Simao Seixas and Berkes, 2010) highlights that Thailand, Pred Nai community developed an informal patrolling program to respond to resource use conflicts and degradation of the mangrove forest. From 1988 to 1997, the community established linkages with only two outside partners, resulting in interactions across only three levels of the organization. Pred Nai advanced from informal patrolling of their mangroves to the establishment of a formal conservation group that actively managed the local mangrove forest. At the beginning of formal management (1998-2002), nine outside partners from five different organizational levels, including government, non-governmental organizations (NGO), university, and other communities through formal and informal networks, had a stake in management. Due to profound interactive alignment between the state, the market and the society, in just four years (2002 - 2006) membership doubled thus the outcome of the program.

Furthermore, in the case of tourism in Vietnam, (Dang, 2016) shows that tourism has been a major factor in job creation, economic development and poverty alleviation since 1990 In 2007 the village was recognized as a cultural heritage of Ha Giang and in 2015 with the help of NGOs after the failure of the first attempt by the community to maintain and develop this area, the local community invested on the construction of basic services such as bathrooms for visitors. (Valdivia, 2015) further postulated that in 2017, the 300-year old village consists of 112 traditional houses with about 560 households and $10 \%$ of the total income from the tourism sector is distributed amongst the entire community. 
In Kenya, (Leting, 2017)conducted a study focussing on examining the kind of communitylevel entrepreneurial activities that have been created and as well as the development progress in improving households' welfare through the collaborative interactions among the society and the government agencies. The two projects that were specifically identified were Nyumba Kumi-initiative and Renewable Energy Kiosk - concept lead by United Nations Industrial Development Organization (UNIDO) for they are rural poverty reduction-oriented projects. Data were gathered through semi-structured and unstructured interviews, observation, e-mail correspondence with key informants, free-form discussions. Respondents included community members, local government officials, and organization representatives to find the impact of these two projects. The results indicated that Renewable Energy Kiosk projects are designed to be financially sustainable thus the state and the society should collaborate in funding risings activities to cover the running and maintenance costs of the projects at their initial stage.

In Laos, the Nam Ha ecotourism project, working closely with local villagers in integrating environmental and cultural conservation with sustainable socio-economic development ensures that tourists' incomes supplement rather than replacing other economic activities of the society. Typically, the community runs all of the activities that a tourist engages in such as lodging, food, guiding and craft sales. This initiative has led to substantial per capita income growth in rural regions and lessened the income gap through equitable distribution of tourism revenue. This has also compelled the community to engage in projects that aim at improving natural resources conservations (Harrison and Schipani, 2007).

In the case of Zambia, (Thompson and MacMillan, 2010) studied the Feeds Project that aimed at producing high-quality, low-cost animal feed in northwest Zambia. Nonetheless, the project 
was faced with several challenges including poor business environment characterized by lack of government intervention, uncollectable debts, distortionary market imperfections emerging from well-established competitors. resultantly, many small-scale farmers lost their confidence in this project. As a comeback strategy, the key stakeholders in this project designed an education program in an attempt to convince the society of the intertemporal benefits of this project. Thereafter, the authors show that gradually the locals began to regain some confidence in this project. The above case of Zambia presents interesting findings by (Naudé, 2010) that in most development projects that fail, the prime cause is that albeit government and development agencies are devoting substantial resources to encourage entrepreneurship majority of entrepreneurship models that are being used might not be suitable for the poor rural communities and no initiative is taken to familiarize the community about these models.

\section{DATA COLLECTION METHODS AND RESULTS ANALYSIS}

\subsection{DATA COLLECTION METHODS}

BEDCO's interest is in the implementation of CBE across the country, however, it uses the three villages in three districts as a pilot study, namely; Mphaki located in Quthing, Mpharane in Mohale's Hoek and finally in Semonkong. The data was collected first hand in the form of face to face questionnaire interviews. We managed to interview a sample of 85 villagers in Mphaki, 107 in Mpharane and then 92 in Semonkong which then totals to 284 villagers interviewed altogether, from age of 18. Based on 2006 Lesotho's Household Survey, which is currently the only household survey available to the public, Mphaki has 150 households with a population of 476 while Mpharane has 69 households with a population of 310. The number 
of households and population data is not available therefore the household size was determined based on the average of questionnaires to be distributed in both Mphaki and Mpharane. SPSS spreadsheet was employed to run the frequency analyses in analysing this data. Results are presented in the subsequent section.

\subsection{RESULTSANDAISCUSSIONS}

\section{BEDCO AWARENESS INDEX}

Table 1: BEDCO Awareness Index

\begin{tabular}{|c|c|c|c|}
\hline \multicolumn{4}{|l|}{ MPHAKI } \\
\hline & FREQUENCY & PERCENT & $\begin{array}{l}\text { CUMMULATIVE } \\
\text { PERCENT }\end{array}$ \\
\hline Full Knowledge & - & - & - \\
\hline Partial Knowledge & 9 & 10.6 & 10.6 \\
\hline No Knowledge & 76 & 89.4 & 100.0 \\
\hline \multicolumn{4}{|l|}{ MPHARANE } \\
\hline Full Knowledge & 3 & 2.8 & 2.8 \\
\hline Partial Knowledge & 12 & 11.2 & 14.2 \\
\hline No Knowledge & 91 & 85.0 & 100.0 \\
\hline \multicolumn{4}{|l|}{ SEMONKONG } \\
\hline Full Knowledge & - & - & - \\
\hline Partial Knowledge & 4 & 4.3 & 4.3 \\
\hline No Knowledge & 88 & 95.7 & 100.0 \\
\hline
\end{tabular}


Table 1 shows frequencies, percentages and cumulative percentages of the three selected villages that were interviewed. The results indicate that out of the three villages, Semonkong shows the least awareness with $95.7 \%$ of the interviewees having no knowledge about BEDCO. Mphaki follows with $89.4 \%$ of no knowledge and followed by Mpharane with $85 \%$ of the interviewees not knowing. This low awareness index may significantly affect the robustness of the rankings of BEDCO rating perception as the rating relies directly on the awareness index. Nonetheless, of these three villages, Mpharane stands out with it being the only village where people were fully aware of BEDCO services, even though only three percent of the respondents who were fully aware. All these three villages had people who have partial knowledge of BEDCO services. In Semonkong $4.3 \%$ of the interviewees had partial knowledge while in Mphaki, $10.6 \%$ of the respondents had a partial knowledge. Mpharane again leads the way in terms of partial awareness about the services with $11.2 \%$ of the respondents having a partial knowledge. The overall results of awareness, however, show that most of the people in these three villages are still not aware of BEDCO and the services it provides. 


\section{KNOWLEDGE OF SPECIFIC DEVELOPMENTS}

Table 2: Knowledge of Specific Developments

\begin{tabular}{|c|c|c|c|}
\hline \multicolumn{4}{|l|}{ МРНАКI } \\
\hline & FREQUENCY & PERCENT & CUMMULATIVE \\
\hline & & & PERCENT \\
\hline Full Knowledge & 1 & 25.0 & 25.0 \\
\hline Partial Knowledge & 2 & 50.0 & 75.0 \\
\hline No Knowledge & 1 & 25.0 & 100.0 \\
\hline \multicolumn{4}{|l|}{ MPHARANE } \\
\hline Full Knowledge & 3 & 42.9 & 42.9 \\
\hline Partial Knowledge & - & - & - \\
\hline No Knowledge & 4 & 57.1 & 100.0 \\
\hline \multicolumn{4}{|l|}{ SEMONKONG } \\
\hline Full Knowledge & - & - & - \\
\hline Partial Knowledge & - & - & - \\
\hline No Knowledge & 1 & 100.0 & 100.0 \\
\hline
\end{tabular}

Table 2 illustrates whether the villagers who knew about BEDCO and their services are aware of specific developments in their area that BEDCO is intending to undertake. The results indicate that in Semonkong, there was only one respondent who was aware that BEDCO had an intention of enterprise development in the area, but the person had no knowledge about any specific enterprise development intentions. However, the number increased in Mpharane, with a total of seven respondents that were aware of specific places in their community that BEDCO had intentions of developing in terms of enterprises. Of these, $42.9 \%$ of them had full knowledge of the specific enterprise developments that were intended. Mphaki then follows 
with a total of four people who had awareness about places in their area that were intended for enterprise development. Out of these four, only one of them knew about specific development intentions and two of them just had partial knowledge. So, these results again show us that Mpharane had the most awareness out of these three villages.

\section{COMMUNITY EXPECTATIONS FROM BEDCO IN RELATIONT TO}

ENTERPRISE DEVELOPMENT

Table 3: Community Expectations from BEDCO

\begin{tabular}{|c|c|c|c|c|c|c|c|c|c|c|}
\hline & & $\begin{array}{l}\text { Industrial } \\
\text { Storehouse } \\
\text { for Potatoes }\end{array}$ & $\begin{array}{l}\text { Market } \\
\text { Shelter }\end{array}$ & $\begin{array}{l}\text { Product } \\
\text { Processing } \\
\text { Machines }\end{array}$ & $\begin{array}{l}\text { Mini } \\
\text { Factory } \\
\text { Shelves }\end{array}$ & $\begin{array}{l}\text { Mohair and } \\
\text { Wool } \\
\text { Machines }\end{array}$ & $\begin{array}{l}\text { Sunflower } \\
\text { Oil } \\
\text { Extractor }\end{array}$ & $\begin{array}{l}\text { Roadside } \\
\text { Station }\end{array}$ & $\begin{array}{l}\text { Tourism } \\
\text { Info } \\
\text { Center }\end{array}$ & $\begin{array}{l}\text { Aloe } \\
\text { Machi } \\
\text { nery }\end{array}$ \\
\hline \multicolumn{11}{|c|}{ MPHARANE } \\
\hline \multirow{5}{*}{$\underset{e}{e}$} & Not at all & - & - & - & - & 1.9 & .9 & - & - & .9 \\
\hline & No & 3.7 & .9 & .9 & 4.7 & .9 & 5.6 & 1.9 & 3.7 & 1.9 \\
\hline & indifferent & 4.7 & 3.7 & 2.8 & 2.8 & 3.7 & 3.7 & 4.7 & 3.7 & 1.9 \\
\hline & yes & 40.2 & 44.9 & 47.7 & 43.9 & 41.1 & 44.9 & 45.8 & 55.1 & 43.9 \\
\hline & Very much & 48.6 & 46.7 & 44.9 & 44.9 & 50.5 & 41.1 & 42.1 & 32.7 & 46.7 \\
\hline \multicolumn{11}{|c|}{ SEMONKONG } \\
\hline \multirow{5}{*}{$\begin{array}{l}+0 \\
e \\
e \\
0 \\
0\end{array}$} & Not at all & 1.1 & 1.1 & 1.1 & 1.1 & 1.1 & 2.2 & 1.1 & 1.1 & 1.1 \\
\hline & No & 3.3 & 5.4 & 1.1 & 1.1 & 2.2 & 4.3 & 1.1 & 2.2 & 2.2 \\
\hline & indifferent & 6.5 & 8.7 & 13.0 & 10.9 & 10.9 & 9.8 & 8.7 & 8.7 & 8.7 \\
\hline & yes & 31.5 & 27.2 & 31.5 & 30.4 & 28.3 & 25.0 & 31.5 & 29.3 & 34.8 \\
\hline & Very much & 57.6 & 52.2 & 47.8 & 52.2 & 53.3 & 53.3 & 52.2 & 54.3 & 48.9 \\
\hline \multirow{5}{*}{$\underset{e}{e}$} & Not at all & 3.5 & 2.4 & 1.2 & 2.4 & 2.4 & 2.4 & - & 1.2 & 1.2 \\
\hline & No & 5.9 & - & 2.4 & 1.2 & - & 5.9 & - & 1.2 & 1.2 \\
\hline & indifferent & 9.4 & 8.2 & 7.1 & 8.2 & 10.6 & 17.6 & 10.6 & 10.6 & 10.6 \\
\hline & yes & 38.8 & $\begin{array}{ll}44.7 \\
\end{array}$ & 43.5 & 50.6 & 44.7 & 40.0 & 49.4 & 42.4 & 42.4 \\
\hline & Very mисh & 38.8 & 43.5 & 37.6 & 31.8 & 37.6 & 27.1 & 35.3 & 38.8 & 38.8 \\
\hline
\end{tabular}


Amongst the villages that were interviewed, there were some varying discrepancies and also some similarities on what services BEDCO could possibly provide for them. Table 3 above shows the ratios of people who were enthusiastic about certain developments (very much percentage), the ones who just said yes, were indifferent, who disliked the development and the ones who did not want it whatsoever, across the 3 villages.

In Mpharane, the top 3 choices the community picked was wool and mohair machines at $50.5 \%$, industrial storehouse for potatoes at $48.6 \%$, and aloe machine and market shelter sharing the third-best choice at $46.7 \%$. Due to the geographical location of Mpharane, it is important to note that it is quite far from access to certain services and these 4 options could be the most required in the village. It is also quite important to note that $5.6 \%$ of the interviewees disliked the sunflower oil extractor which could show us that the plantation of sunflower is low in this region. In Semonkong, the top three preferences from villagers were industrial storehouses of potatoes at $57.6 \%$, wool and mohair machines at $53.3 \%$ and lastly market shelter and minifactories shelves at $52.2 \%$. It seems agriculture is quite high in Semonkong, even though it is mostly subsistence, the data tell us that agricultural businesses can boom in these village. This is similar to that of Mpharane, with the highest ranging choices being wool and mohair machines followed by industrial storehouse for potatoes. However, unlike Mpharane, residents of Semonkong disliked the idea of having a market shelter with a high ratio of $5.4 \%$.

However, this was not the case in Mphaki as market shelter the highest enthusiastic ratio of 44.7\%. But it is quite important that Mphaki had the lowest enthusiasm ratios and due to that, the 'yes' responses were used to conclude which services were preferred in this villages. The highest 'yes' ratios were shown towards mini-factory shelves, with roadside station following 
with a $49.4 \%$ ratio. Market shelter which had the highest enthusiasm had a $44.7 \%$ ratio, which is similar to wool and mohair. The emphasis in Mphaki is based on selling or market shelters which could imply either (1) the people of Mphaki have something to sell or, (2) there aren't enough locations whereby buying and selling takes place. Mphaki does not only exert a difference in their preferences but also in the service mostly disliked. Industrial storehouse for potatoes and sunflower oil extractors are the highest-ranked services which were disliked, which is quite bizarre considering Mphaki is well known across the country as being a village with rich soil.

In terms of natural resource availability, there are quite some similarities in resources the villagers believed are available. There are high levels of water and aloe across all the three villages accordingly and low levels of clay. In terms of water, $34.1 \%$ of respondents believed there was water in Mphaki, whilst 25\% and 39.3\%, being their highest rating, was present in Semonkong and Mpharane respectively. Aloe had the second highest-rated natural resources with Mphaki, Semonkong and Mpharane tallying 28.2\%, 20.7\%, 38.3\% respectively. With Semonkong however, it is crucial to state that $21.9 \%$ of respondents stated there were no natural resources and unlike other villages, it was the second-highest ranking in Semonkong. In Mphaki no responses were $27.1 \%$ whilst Mpharane had the lowest with $14 \%$. The lowest natural across the three villagers was clay tallying $12.9 \%$ in Mphaki and 21.5\% in Mpharane. In Semonkong, clay tallied low at $15.7 \%$ the same as Rose hip although Rose hip tallied at $31.8 \%$ in Mpharane, being the third highest resource. Data show that there should be focus on water and aloe across all the three villages and Rose hip in Mpharane whilst clay business should not develop across all three villages 

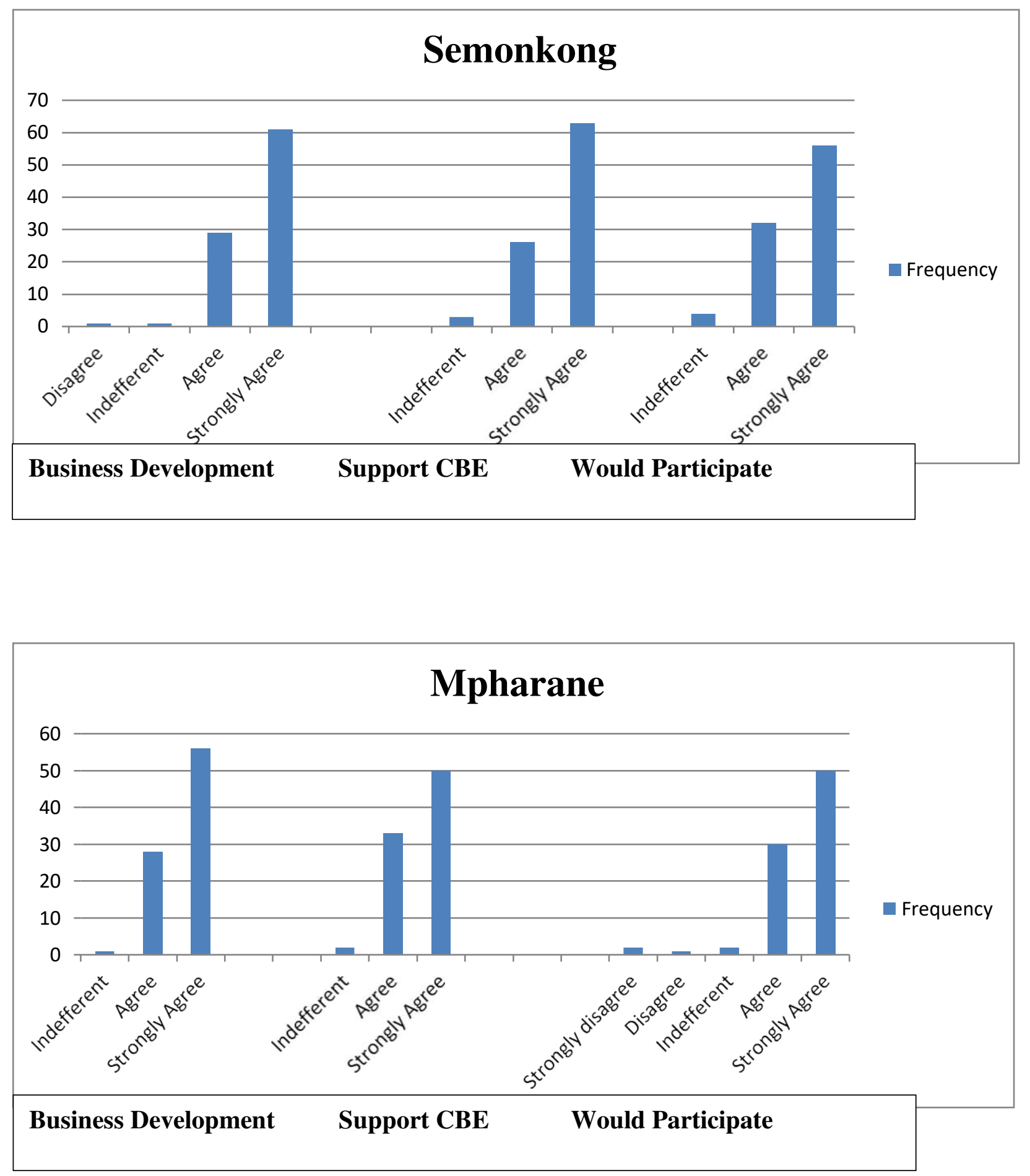


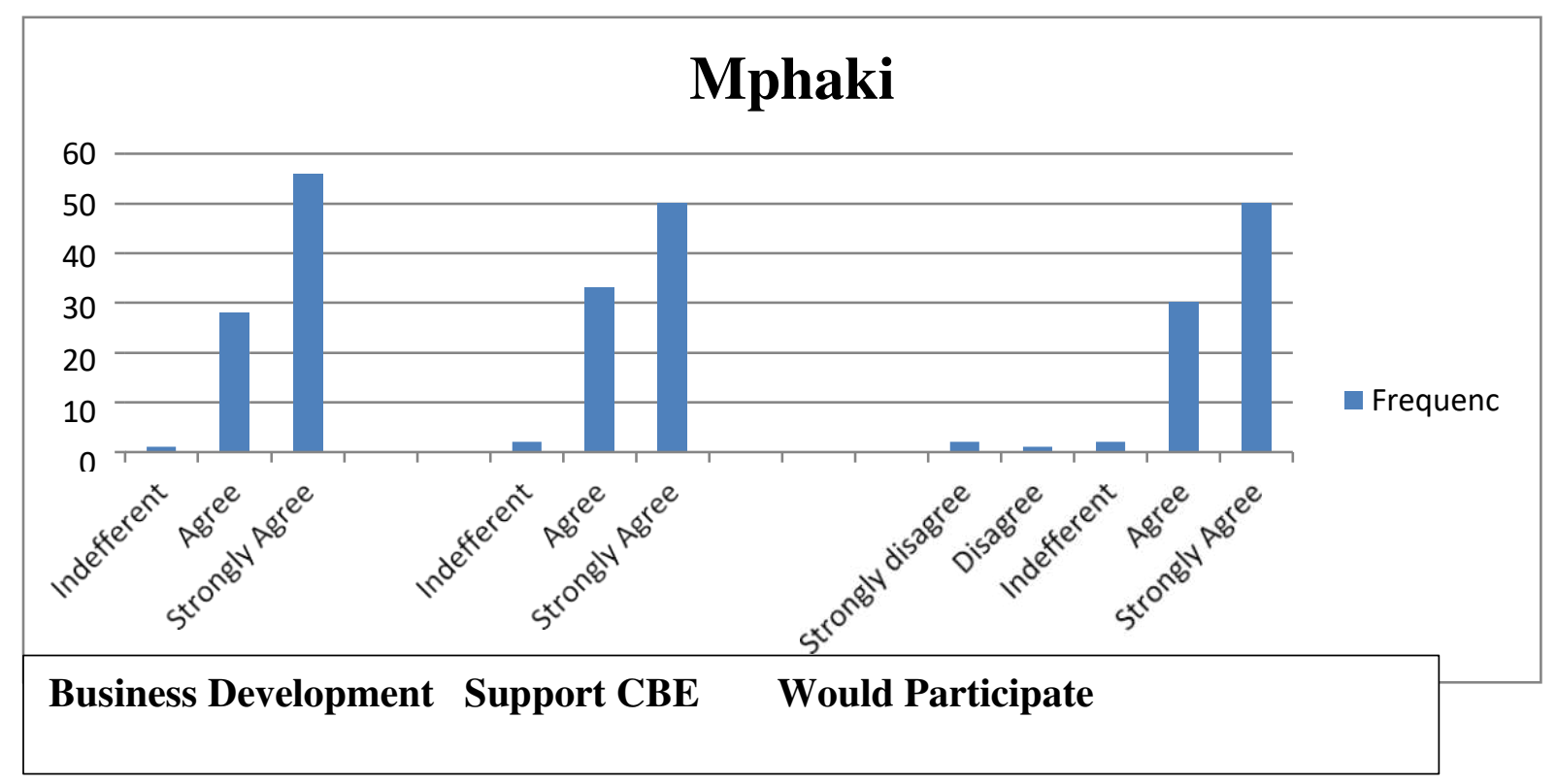

Figures 4-6: Community's Perspective on CBE

Out of 92 people interviewed in Semonkong, a high fraction of $66.3 \%$ of people loved the idea of business development in their areas, with Mphaki closely following with $65.9 \%$ then Mpharane with $64.5 \%$. Likewise, the order of ratings is similar to the fraction of people who would support business development. Semonkong was high with 68.5\%, followed by Mphaki with 58.8\% then Mpharane with 55.1\%. Notably, the amount of people who said they would support business development is higher than people who said they love business development, unlike Mphaki and Mpharane. Semonkong had the highest fraction of people who said they would take initiative with $60.9 \%$ whilst in Mpharane it was $59.8 \%$ Mphaki had the lowest fraction of people who said they take part in business development in their community with $58.8 \%$. 


\section{C O N C L U S I O N}

The objective of this study was to assess community perception on community-based entrepreneurship through a case study approach with an implicit research question on how BEDCO can contribute in enhancing livelihood development and thus sustaining the community at large with particular attention on addressing the following questions: (1) what are communities' perspectives about community-based enterprises? (2) What local natural resources are available that can be utilized for the community's entrepreneurial purposes? (3) What are communities' expectations from BEDCO in relation to enterprise development? Finally, the study will seek to determine 'BEDCO - community' awareness index which captures the scale at which BEDCO roles are known within rural communities. Enthusiasm is high in all villages as a majority of interviewees showed a positive initiative capacity in which the only barrier pulling them back is a pushing force. This barrier can be justified as the majority of people have no knowledge of BEDCO and the services they provide. Therefore, means to public awareness about BEDCO remain the central catalyst for CBE. Nevertheless, each village has significant number of natural resources that can be entrepreneurially explored to create a successful niche that can benefit the community through government assistance. Regarding communities' expectations from BEDCO, the study identified the top three expectations from each village, making it easy for BEDCO to sequence its assistance to these communities. Finally, with the harmonized interaction between the state, the market and the society in community development that is based on the conspicuous needs of the community, CBEs stand a better chance of success as community which is central in CBEs will be in the frontline of all CBEs activities. To sum up, the main conclusion it that, central to CBE in Lesotho is the participation of BEDCO as well as the interaction between the state, the market and the society. BEDCO is particularly important in financing and facilitating CBEs, while the 
interaction of the state the market and the society ensure the only the support of the CBEs, but also their sustainability in promoting a better welfare for rural communities through employing available community resources.

\section{I S T O F A B B R E V I A T I O N S}

1. BEDCO - Basotho Enterprises Development Corporation

2. CBE - Communal-Based Enterprises

3. GDP - Gross Domestic Product

4. LDC - Least Developed Countries

5. MSME - Micro-Small Medium Enterprise

6. NGO - Non-Governmental Organizations

7. SSA - Sub-Saharan African

8. UNIDO - United Nations Industrial Development Organization

D E C L A RA T I O N S

Ethical Approval and Consent to Participate: the study received approval from BEDCO research team.

Consent for Publication: this manuscript in part or in full has not been submitted or published anywhere and the manuscript will not be submitted elsewhere until the editorial process is completed. 
Availability of data and material: By publishing in this journal, the authors agree that, any materials and data that will be requested by other will be made available in timely manner, at reasonable cost.

Competing Interest: The authors declare no competing financial interests.

Funding: no research funding has been offered for this research.

Authors' Contributions: Makhetha S. Leseko made a substantial contribution to the Background and Literature review of the study. Liphoto R. Ramakae, Mahamo S. Makara, Manong S. Nkopane, and Mokhethi A. Motlalepula gave a huge contribution in designing the study, data collection as well as results analysis. Finally, all authors approved the final version of the study.

Acknowledgements: the authors give special thanks for BEDCO research team for financing all data collection trips, and for printing out of all the questionnaires. The authors are also grateful for the Department of Economic at the National University of Lesotho for freely allowing final year B.A. Economics students to participate in data collection. Gratitude appreciation also goes Professor Makatjane in the Department of Statistics at the National University of Lesotho for his technical support in this study. Finally, the authors share their warm gratitude with the respondents to the lengthy questionnaires. 


\section{R E F E R E N C E S:}

1. Cavaye, J. (2001) 'Rural community development - New challenges and enduring dilemmas', Journal of Regional Analysis and Policy.

2. Cheema, A. A. and Shah, F. H. (1987) 'Pesticide residues in fruits and vegetables', PAK. J. SCI. IND. RES. doi: 10.5772/13440.

3. Dang, T. T. D. (2016) 'Vietnamese EFL Students' Perceptions of Noticing-Based Collaborative Feedback on Their Writing Performance', English Language Teaching. doi: 10.5539/elt.v9n5p141.

4. Eclac-un, A. et al. (2002) 'Promoting Growth And Welfare : Structural Changes And The Role Of Institutions In Asia Building the Indonesian Economy anew and pivotal role of corporate reform'.

5. Harrison, D. and Schipani, S. (2007) 'Lao tourism and poverty alleviation: Communitybased tourism and the private sector', Current Issues in Tourism. doi: 10.2167/cit310.0.

6. Hughey, J., Speer, P. W. and Peterson, N. A. (1999) 'Sense of community in community organizations: Structure and evidence of validity', Journal of Community Psychology. doi: 10.1002/(SICI)1520-6629(199901)27:1<97::AID-JCOP7>3.0.CO;2-K.

7. Khoase, R. G. and Govender, K. K. (2013) 'Enhancing small, medium and micro enterprise development: Exploring selective interventions by the Lesotho government', Development Southern Africa. doi: 10.1080/0376835X.2013.834814.

8. Klees, S. J. (2008) 'A quarter century of neoliberal thinking in education: misleading analyses and failed policies', Globalisation, Societies and Education. doi: 10.1080/14767720802506672.

9. 'Lesotho 2015' (2015) Africa Economic Outlook. Available at: 
http://www.africaneconomicoutlook.org/fileadmin/uploads/aeo/2015/CN_data/CN_Lon g_EN/Lesotho_GB_2015.pdf.

10. Leting, M. (2017) 'Nyumba Kumi Strategy of Community Policing And Its Impact on Curbing Crime; Empirical Assessment From Kenya.', IOSR Journal of Humanities and Social Science. doi: 10.9790/0837-2201043236.

11. Liñán, F. and Santos, F. J. (2007) 'Does social capital affect entrepreneurial intentions?', International Advances in Economic Research. doi: 10.1007/s11294-007-9109-8.

12. Martin, R. L. and Osberg, S. R. (2015) 'Two keys To sustainable social enterprise.', Harvard Business Review.

13. Murphy, W. J. (1948) 'Annual Reviews', Analytical Chemistry, 20(8), p. 689. doi: 10.1021/ac60020a001.

14. National Institute of Statistics, Directorate General for Health and ICF International (2015) Lesotho Demographic and health survey 2014, Lesotho Ministry of Health.

15. Naudé, W. (2010) 'Entrepreneurship, developing countries, and development economics: New approaches and insights', Small Business Economics. doi: 10.1007/s11187-0099198-2.

16. Parwez, S. (2017) 'Community-based entrepreneurship: evidences from a retail case study', Journal of Innovation and Entrepreneurship. doi: 10.1186/s13731-017-0074-z.

17. Peredo, A. M. and Chrisman, J. J. (2006) 'Toward a theory of community-based enterprise', Academy of Management Review. doi: 10.5465/AMR.2006.20208683.

18. Pittaway, L. and Thorpe, R. (2012) 'Entrepreneurship \& Regional Development An International Journal A framework for entrepreneurial learning: A tribute to Jason Cope A framework for entrepreneurial learning: A tribute to Jason Cope', Entrepreneurship \& Regional Development. doi: 10.1080/08985626.2012.694268. 
19. Portes, A. (2009) 'Social capital: Its origins and applications in modern sociology', in Knowledge and Social Capital. doi: 10.1146/annurev.soc.24.1.1.

20. Schütte, G. (2018) 'What kind of innovation policy does the bioeconomy need?', New Biotechnology. doi: 10.1016/j.nbt.2017.04.003.

21. Simao Seixas, C. and Berkes, F. (2010) 'Community-based enterprises : the significance of partnerships', International Journal of the Commons.

22. Stiglitz, J. E. (1996) 'Some lessons from the East Asian miracle', World Bank Research Observer. doi: 10.1093/wbro/11.2.151.

23. Thompson, J. D. and MacMillan, I. C. (2010) 'Business models: Creating new markets and societal wealth', Long Range Planning. doi: 10.1016/j.lrp.2009.11.002.

24. United Nations (2001) 'WORLD INVESTMENT REPORT 2001', in Promoting linkages.

25. Valdivia, M. (2015) 'Business training plus for female entrepreneurship? Short and medium-term experimental evidence from Peru', Journal of Development Economics. doi: 10.1016/j.jdeveco.2014.10.005.

26. World Bank (2018) 'The Human Capital Project in Sub-Saharan Africa: Stories of Progress'. Available at: https://www.worldbank.org/en/region/afr/publication/thehuman-capital-project-in-sub-saharan-africa-stories-of-progress.print.

27. World Urbanization Prospects: The 2018 Revision (2019) World Urbanization Prospects: The 2018 Revision. doi: 10.18356/b9e995fe-en. 
Figures

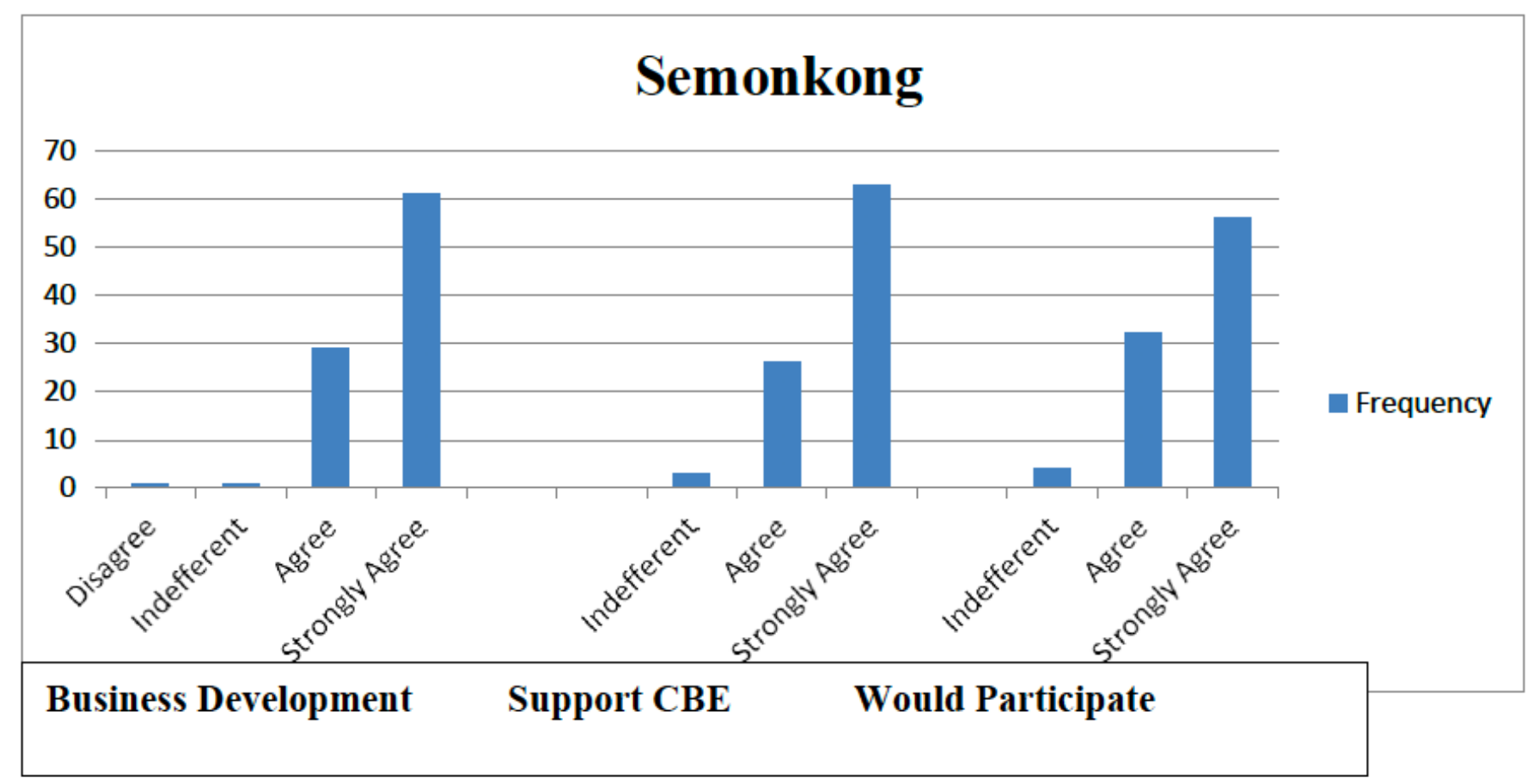

Figure 1

Community's Perspective on CBE 


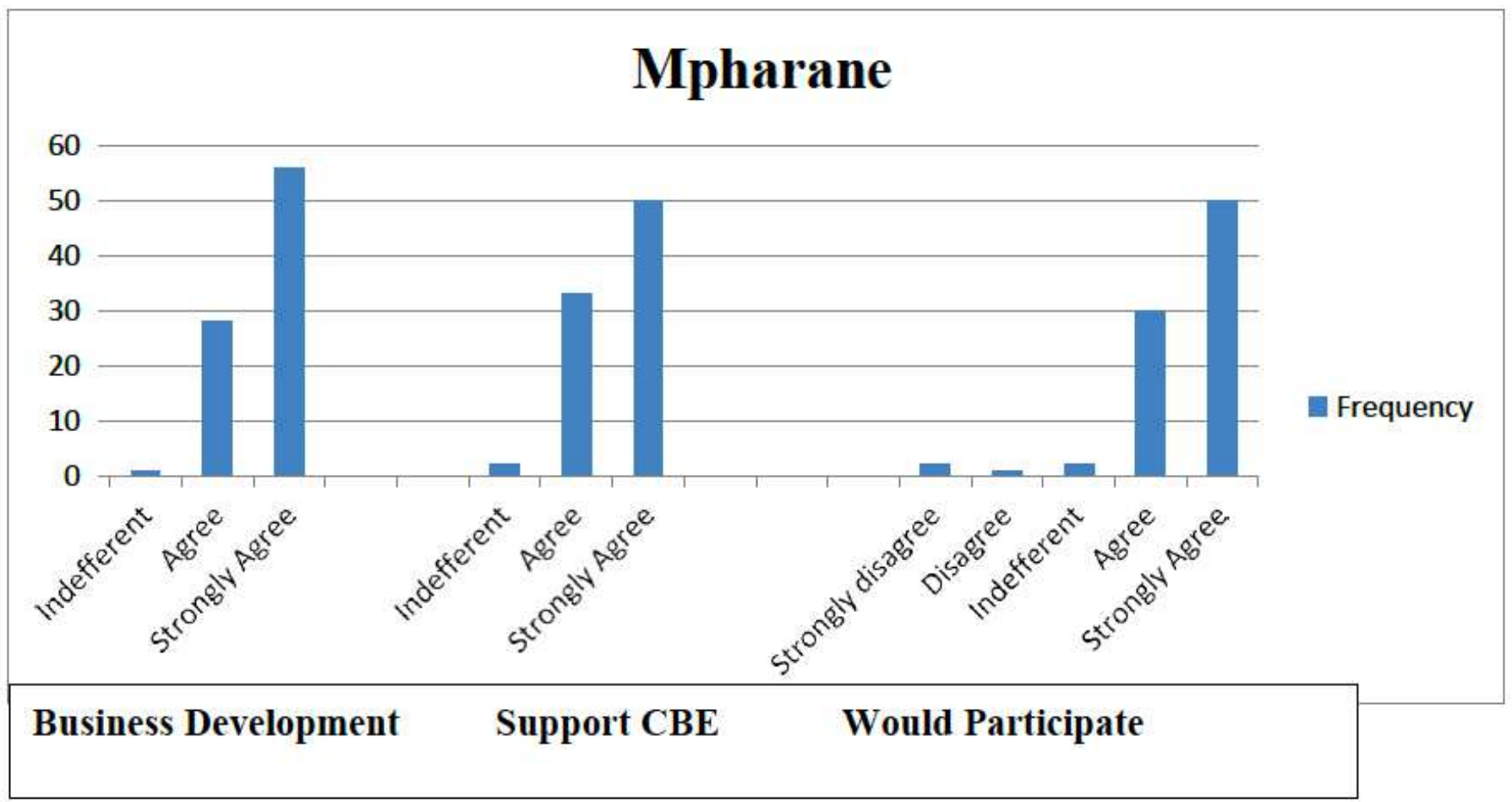

Figure 2

Community's Perspective on CBE

\section{Mphaki}

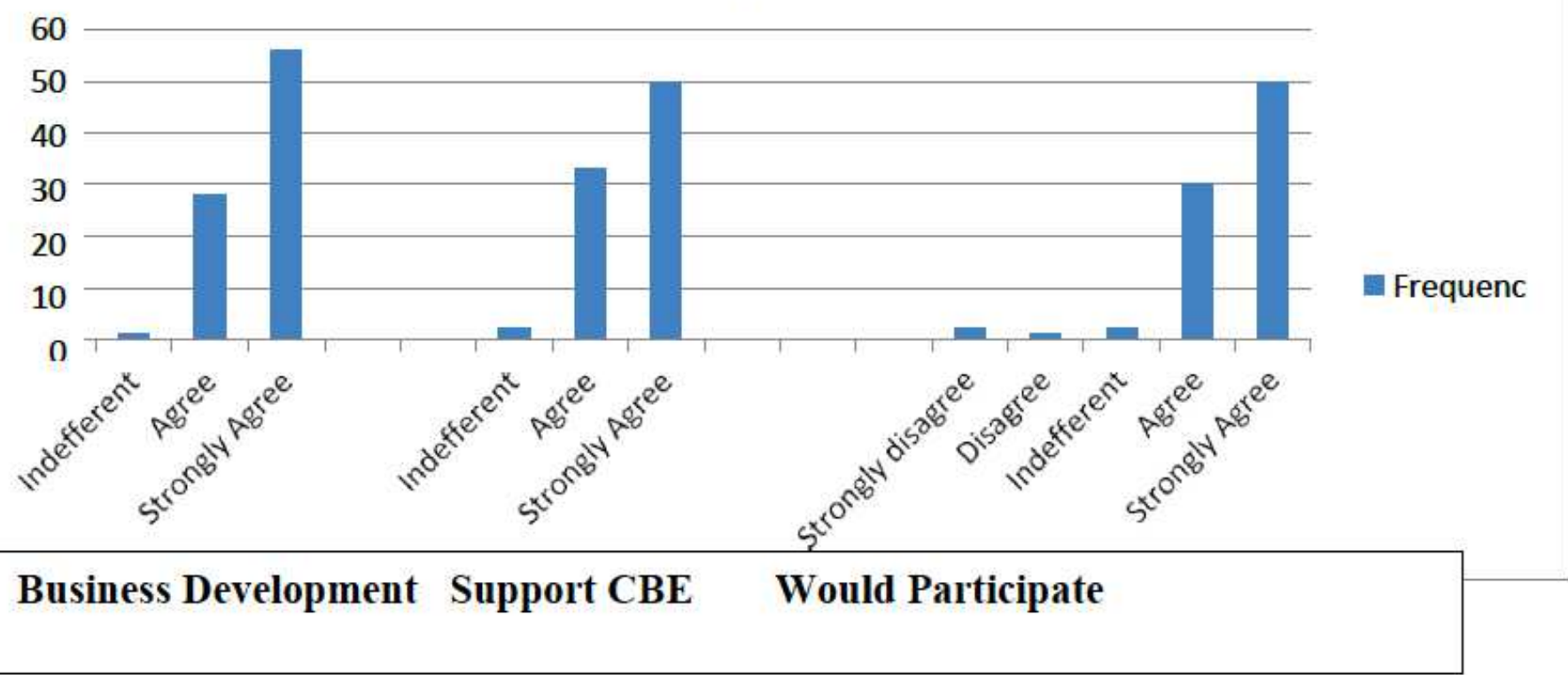

Figure 3 
Community's Perspective on CBE 